\title{
Challenges of including human exposure to chemicals in food packaging as a new exposure pathway in life cycle impact assessment
}

\author{
Ernstoff, Alexi; Muncke, Jane; Niero, Monia; Trier, Xenia; Rosenbaum, Ralph K.; Hauschild, Michael \\ Zwicky; Fantke, Peter
}

Published in:

International Journal of Life Cycle Assessment

Link to article, DOI:

10.1007/s11367-018-1569-y

Publication date:

2019

Document Version

Peer reviewed version

Link back to DTU Orbit

Citation (APA):

Ernstoff, A., Muncke, J., Niero, M., Trier, X., Rosenbaum, R. K., Hauschild, M. Z., \& Fantke, P. (2019). Challenges of including human exposure to chemicals in food packaging as a new exposure pathway in life cycle impact assessment. International Journal of Life Cycle Assessment, 24(3), 543-552. https://doi.org/10.1007/s11367-018-1569-y

\section{General rights}

Copyright and moral rights for the publications made accessible in the public portal are retained by the authors and/or other copyright owners and it is a condition of accessing publications that users recognise and abide by the legal requirements associated with these rights.

- Users may download and print one copy of any publication from the public portal for the purpose of private study or research.

- You may not further distribute the material or use it for any profit-making activity or commercial gain

- You may freely distribute the URL identifying the publication in the public portal 


\section{Challenges of including human exposure to chemicals in food packaging as a new exposure pathway in life cycle impact assessment}

Alexi Ernstoff, $1 \times$

Email alexi.ernstoff@quantis-intl.com

Monia Niero, 1,2

Jane Muncke, 3

Xenia Trier, 4,5 
Ralph K. Rosenbaum, 6

Michael Hauschild, 1

Peter Fantke, 1

${ }^{1}$ Quantitative Sustainability Assessment Division, Department of Management Engineering, Technical University of Denmark, Diplomvej 371, 2800 Kgs. Lyngby, Denmark AQ1

2 Department of Planning, Aalborg University, A.C. Meyers Vaenge 15, 2450 Copenhagen, Denmark

${ }^{3}$ Food Packaging Forum Foundation, Staffelstrasse 8, 8045 Zurich, Switzerland

4 Analytical Food Chemistry, National Food Institute, Technical University of Denmark, 2800 Kgs. Lyngby, Denmark

5 European Environment Agency, Kongens Nytorv

6, 1050 Copenhagen, Denmark

6 IRSTEA, UMR ITAP, ELSA LCA Research Group \& ELSA-PACT Industrial Chair, 361 rue Jean-François Breton, BP 5095, 34196 Montpellier, France

Received: 4 April 2017 / Accepted: 27 November 2018

\section{Abstract}

\section{Purpose}

Limiting exposure to potentially toxic chemicals in food packaging can lead to environmental impact trade-offs. No available tool, however, considers tradeoffs between environmental impacts of packaging systems and exposure to potentially toxic chemicals in food packaging. This study therefore explores the research needs for extending life cycle impact assessment (LCIA) to include exposure to chemicals in food packaging.

\section{Methods}


The LCIA framework for human toxicity was extended for the first time to include consumer exposure to chemicals in food packaging through the product intake fraction (PiF) metric. The related exposure pathway was added to LCIA without other modifications to the existing toxicity characterization framework used by USEtox ${ }^{\circledR}$, i.e., effect factor derivation. The developed method was applied to a high impact polystyrene (HIPS) container case study with the functional unit of providing $1 \mathrm{~kg}$ of yogurt in single servings. Various exposure scenarios were considered, including an evidence-based scenario using concentration data and a migration model. Human toxicity impact scores in comparative toxic units $\left(\mathrm{CTU}_{\mathrm{h}}\right)$ for the use stage were evaluated and then compared to human toxicity impact scores from a conventional LCIA methodology.

\section{Results and discussion}

Data allowed toxicity characterization of use stage exposure to only seven chemicals in HIPS out of fourty-four identified. Data required were the initial concentration of chemicals in food packaging, chemical mass transfer from packaging into food, and relevant toxicity information. Toxicity characterization demonstrated that the combined $\mathrm{CTU}_{\mathrm{h}}$ for HIPS material acquisition, manufacturing, and disposal stages exceeded the toxicity scores related to consumer exposure to previously estimated concentrations of the seven characterizable chemicals in HIPS, by about two orders of magnitude. The $\mathrm{CTU}_{\mathrm{h}}$ associated with consumer exposure became relevant when migration was above $0.1 \%$ of the European regulatory levels. Results emphasize missing data for chemical concentrations in food contact materials and a need to expand the current USEtox method for effect factor derivation (e.g., to consider endocrine disruption, mixture toxicity, background exposure, and thresholds when relevant).

\section{Conclusions}

An LCIA method was developed to include consumer exposure to chemicals in food packaging. Further study is required to assess realistic scenarios to inform decisions and policies, such as circular economy, which can lead to trade-offs between environmental impacts and potentially toxic chemicals in packaging. To apply the developed method, data regarding occurrence, concentration, and toxicity of chemicals in food packaging are needed. Revisiting the derivation of effect factors in future work could improve the interpretation of human toxicity impact scores. 


\section{Keywords}

Food contact materials

Human toxicity potential

Near-field exposure

Risk assessment

Responsible editor: Hans-Jürgen Garvens

Electronic supplementary material

The online version of this article ( https://doi.org/10.1007/s11367-018-1569-y ) contains supplementary material, which is available to authorized users.

\section{Introduction}

Life cycle assessment (LCA) is a decision-support tool used by regulatory, academic, and industrial stakeholders to quantify and compare the environmental performance of product or service systems over their life cycle. LCA has for many years been applied to compare different food and beverage packaging systems (Hunt and Franklin 1996; Humbert et al. 2009; Belboom et al. 2011; Flanigan et al. 2013; Gérand and Roux 2014; Dhaliwal et al. 2014). As an integral part of any-LCA-study, life cycle impact assessment (LCIA) methods quantify potential impacts on ecosystems, resources, and human health due to the input (resource uses) and output (emissions) flows inventoried for a defined product system. A product system and the magnitude of associated flows are modeled with respect to a functional unit (e.g., one or one million disposable containers to deliver single servings of yogurt) describing the service provided by the system. Human toxicity is one human health impact category in LCIA and is currently quantified by characterizing the impact pathway from chemical emissions, environmental fate, human exposure (usually estimated through a mass-balance model), and effects (Hauschild and Huijbregts 2015; Jolliet and Fantke 2015).

The Life Cycle Inventory (LCI) phase of LCA accounts for the chemical emissions to the environment that are associated with a product system's life cycle and, accordingly, LCIA methods typically quantify human exposure pathways associated with inventoried environmental emissions. To address major exposure pathways currently missing in LCIA, recent method developments focus on indoor or near-field exposure pathways associated with consumer products and occupational settings (Hellweg et al. 2009; Jolliet et al. 2015; Rosenbaum et al. 2015; Fantke et al. 2016; Csiszar et al. 2016b; Pini et al. 2016). Such developments are important, since the exposure modeling framework in 
LCIA generally aims to capture all exposure pathways related to the modeled product system, regardless of existing safety regulations which can vary through time and regionally (Jolliet and Fantke 2015). The goal of including all relevant exposure pathways in LCIA is to facilitate the best possible comparison of the performance across product systems with respect to human toxicity, and within a multi-impact indicator framework. New methods, for example, have been developed to add exposure pathways related to the use of cosmetics (Ernstoff et al. 2016) and other consumer products to LCIA (Jolliet et al. 2015; Huang and Jolliet 2016; Fantke et al. 2016; Csiszar et al. 2016b). Methods are currently, however, still missing to estimate exposure to chemicals migrating from food packaging into food, which is a major exposure pathway for a variety of potentially toxic chemicals with implications for human health (Poças and Hogg 2007; Muncke 2011; FDA 2015a; Karmaus et al. 2016).

Human toxicity characterization in LCIA is one distinct strategy for management of human exposure to potentially toxic chemicals with respect to a product system. The key advantages to this strategy are being able to compare the human toxicity impacts of different product systems, life cycle stages, and alongside other life cycle impacts on human health, ecosystems, and resources. Safety regulations, that for example set chemical-specific limits for allowable migration from a material into a food, are a management strategy specific to controlling exposure to potentially toxic chemicals in food packaging materials (EC 2011; FDA 2016). The main advantages of safety regulations are to focus on protecting human health and providing a regulatory framework for doing so. Many epidemiology studies have, however, found associations between human outcomes (e.g., anogenital distance, asthma) and exposure to chemicals, most notably phthalates and fluorinated compounds, which occur in food contact materials (Swan et al. 2005; Apelberg et al. 2007; Jaakkola and Knight 2008; Prüss-Ustün et al. 2011; Bach et al. 2015; Ejaredar et al. 2015). Overall, generating direct evidence that current exposure to chemicals that have migrated from packaging materials to food can increase disease risk is a resourceintensive, largely unresolved, epidemiological challenge. Given the difficulty in estimating the human disease risk related to chemicals in food contact materials, gaps in safety regulations (e.g., lacking toxicity data, and no specific regulations for chemicals in paper and board), and delays between generation of scientific evidence and legislation (Biedermann and Grob 2013; Maffini et al. 2013; Neltner et al. 2013; Kortenkamp 2014; EFSA 2017) other prioritization and screening methods have emerged to manage exposure to chemicals in food packaging materials, for example based on toxicity modeling (Oldring et al. 2014; Biryol et al. 2015; Karmaus et al. 2016). 
Management issues related to chemicals in food packaging remain that cannot be addressed by current LCIA methods, safety regulations, and other recent advances in screening tools for chemicals in food packaging materials. Specifically, there are no methods available that can compare and consider burden shifting between human exposure to potentially toxic chemicals in food packaging, and other impacts on human health, ecosystems, and resources related to a food packaging system. Examples of such burden shifting include controls on functional barriers (Begley and Hollifield 1995) and recycled content (European Parliament 2015; FDA 2015b) to limit the migration of potentially toxic chemicals from packaging into food, but as consequence increase material and associated resource requirements (Lee et al. 2014; European Bureau for Conservation and Development 2015; DG Environment, EC 2016; World Economic Forum and Ellen MacArthur Foundation 2016; Leslie et al. 2016). Furthermore, there is no tool available that can identify areas of priority over product life cycles (e.g., to compare production and use stage) to minimize the potential for human exposure to potentially toxic chemicals.

Quantitative impact assessment approaches that holistically cover various life cycle stages and impact categories are one way to help ensure that specific management targets do not introduce trade-offs by increasing other impacts, or lead to regrettable decisions (Fantke et al. 2015; Pelletier 2015). LCłA can thus be explored as a management strategy to address trade-offs between potential toxicity of chemicals in packaging materials and environmental burdens over the packaging life cycle. In the study, we therefore focus on answering the following questions:

1. How can exposure to chemicals migrating from packaging into food be incorporated into LCIA to complement the other exposure pathways currently considered in toxicity characterization methods?

2. What are the implications of and next steps toward incorporating exposure to migrants and subsequent human toxicity impacts within LCIA?

To answer these questions, we first add the exposure pathway for chemicals migrating from packaging into food in an LCIA methodological framework. We then apply the framework in a proof-of-concept screening of a polymeric packaging system in Europe, where exposure to chemicals in the food packaging material is considered within the LCIA toxicity characterization framework. The purpose of this case study is not to obtain representative results but to elucidate the feasibility and research needs for including chemicals migrating from packaging into food in LCIA. Lastly, we discuss the conceptual conflicts tied to reporting human toxicity impact scores as comparative toxic units $\left(\mathrm{CTU}_{\mathrm{h}}\right)$ for 
food packaging materials, and the needed steps to improve LCIA result interpretation.

\section{Methods}

\subsection{Human toxicity characterization in LCIA}

In this study, a new exposure pathway is added to the existing exposure modeling framework in LCIA as described in the following section. The scientific consensus methods from USEtox ${ }^{\circledR}$ (Hauschild et al. 2008; Rosenbaum et al. 2008,2011 ) were then used as the LCIA framework for toxicity characterization and quantification of human health impact. The LCIA framework for human toxicity characterization is currently comprised of an intake fraction (iF) and effect factor (EF). The iF and EF are combined to obtain a human toxicity potential characterization factor $(\mathrm{CF})$. Human toxicity impact scores, $\mathrm{CTU}_{\mathrm{h}}$ represented as human disease cases, are then derived by combining the $\mathrm{CF}$ with LCI emissions as follows (Jolliet and Fantke 2015):

$$
\mathrm{IS}_{\mathrm{e}}=\mathrm{m}_{\mathrm{e}} \times \mathrm{iF} \times \mathrm{EF}=\mathrm{m}_{\mathrm{e}} \times \mathrm{CF} .
$$

$\mathrm{AQ2}$

$\mathrm{IS}_{\mathrm{e}}$ is the human toxicity impact score as $\mathrm{CTU}_{\mathrm{h}}$ (disease cases per FU) caused by a chemical mass emitted to the environment, $\mathrm{m}_{\mathrm{e}}$ ( $\mathrm{kg}$ emitted per $\mathrm{FU}$ ), which is ultimately taken in by the human population according to $\mathrm{iF}$ ( $\mathrm{kg}$ taken in per $\mathrm{kg}$ emitted) and linked to a given effect according to EF (disease cases per kg taken in) (Jolliet and Fantke 2015). EFs represent non-cancer and cancer effects as determined in animal experiments, and following USEtox ${ }^{\circledR}$ methods (Hauschild et al. 2008; Rosenbaum et al. 2008, 2011), EFs are extrapolated from doseresponse measures such as the no observed adverse effect level (NOAEL, $\mathrm{mg} / \mathrm{kg} /$ day). Effect factors are extrapolated as a linear dose-response relationship where zero exposure leads to zero effect, and there is no effect threshold considered (Rosenbaum et al. 2011). There are two total human toxicity impact scores per FU separately aggregated for cancer and non-cancer effects which can be associated with different average statistical disease cases to estimate ultimate human health damage (Huijbregts et al. 2005). Given this quantitative framework, CTUh scores are not to be interpreted as measurable or predictable actual disease cases. Instead, CTUh are comparative scores, derived from an internally consistent framework that considers a population's modeled intake of the chemicals inventoried with available effect factors. CTUh therefore accounts for the magnitude of modeled intake for an exposed population and a marginal change on the respective extrapolated dose-response curve, for each chemical. With that, human toxicity impact scores represent one category out of many 
impact scores used in the LCIA characterization framework (Hauschild and Huijbregts 2015). More information on LCIA methods for human toxicity characterization is available in the Supporting Information (SI), Section S1 and in other sources (Rosenbaum et al. 2011; Jolliet and Fantke 2015).

\subsection{Exposure and characterization of chemicals in food packaging}

In this study, we extend the existing LCIA toxicity characterization framework described above to include exposure to chemicals migrating from packaging into food. We harmonize this method extension with other recent works focused on including exposure to consumer products in LCIA using the product intake fraction (PiF) metric (Ernstoff et al. 2016; Fantke et al. 2016; Csiszar et al. 2016a; Huang et al. 2017).

$\mathrm{PiF}$ is analogous to $\mathrm{iF}$ but accounts for exposure to the chemical mass originally in a product (Jolliet et al. 2015). Using PiF allows accounting for consumer exposure to chemicals in products, which is generally a missing exposure pathway in LCIA. PiF is the total mass of a chemical taken in, $\mathrm{m}_{\mathrm{ex}}$, versus the original mass of the chemical in a product, $\mathrm{m}_{\mathrm{P}, 0} ; \mathrm{PiF}=\mathrm{m}_{\mathrm{ex}} / \mathrm{m}_{\mathrm{P}, 0}$. For food packaging, $\mathrm{PiF}$ accounts for the fraction of a chemical originally in the package that migrates into the food and the fraction of food consumed-assuming that other exposure pathways are negligible (e.g., dermal contact with the package, and environmental exposures to post-use emissions).

The mass of ingredients initially in a food package, $\mathrm{m}_{\mathrm{P}, 0}$, is often proprietary information that at times can be shared between a study commissioner and an LCA practitioner, e.g., via a non-disclosure agreement. This mass in food package then needs to be linked to the fraction that migrates into the packaged food that is subsequently consumed by humans-conceptually, this is the pathway that is covered in this study by $\mathrm{PiF}$. In some cases, the migrated chemical content in food is directly available from measurements. Whenever such data are not available, which is the case for most chemicals, we propose that $\mathrm{PiF}$ is estimated using a migration model, for example as described in (Begley et al. 2005; Genualdi et al. 2014).

When PiF is obtained, quantification of related impacts follows as

$$
\mathrm{IS}_{\mathrm{P}}=\mathrm{m}_{\mathrm{P}, 0} \times \mathrm{PiF} \times \mathrm{EF}
$$

where, aligned with the iF-based framework (Sect. 2.1, Eq. 1), IS $\mathrm{P}_{\mathrm{P}}$ is the potential impact (disease cases) resulting from the mass of chemical initially in the package, $\mathrm{m}_{\mathrm{P}, 0}(\mathrm{~kg})$, that is taken in by humans according to $\mathrm{PiF}(\mathrm{kg} / \mathrm{kg})$, 
linked to a given potential effect according to EF (disease cases $/ \mathrm{kg}$ ). Two total $\mathrm{IS}_{\mathrm{P}}$ are calculated per FU by aggregating scores separately for cancer and noncancer effects.

When measured or otherwise estimated food concentrations are available, this information can be directly used (without need to estimate $\mathrm{PiF}$ ) for characterization, as

$$
\mathrm{IS}_{\mathrm{P}}=\mathrm{C} \times \mathrm{m}_{\mathrm{f}} \times \mathrm{EF}
$$

where $\mathrm{C}$ is the weight per weight $(\mathrm{kg} / \mathrm{kg})$ concentration of a chemical in a food or beverage (due to migration from packaging), $\mathrm{m}_{\mathrm{f}}(\mathrm{kg})$ is the mass of food or beverage ultimately consumed per FU, and EF is the effect factor.

\subsection{Screening-level LCA case study of a HIPS food packaging system}

A proof-of-concept case study was performed to specifically provide quantitative context for including exposure to chemicals in packaging in LCIA. This case study is a screening-level assessment of one packaging system (i.e., covering life cycle processes using database entries) and is not intended as a comprehensive or ISO-compliant LCA for the tested food packaging system. We considered the functional unit "to deliver and contain $1 \mathrm{~kg}$ of yogurt for single servings." Highimpact polystyrene (HIPS) was considered as an example packaging material with data available and not as a priority material for assessing impacts on human health. Any packaging material can be considered in the described methodology. Single servings of yogurt were set to $125 \mathrm{~mL}$ to define the reference flows for the packaging material. LCI was built using ecoinvent (in priority) (Weidema et al. 2013) and European Life Cycle Database (ELCD) processes for LCI (JRC 2015). For impact characterization, we applied the International Reference Life Cycle Data System (ILCD) LCIA method (EC-JRC 2014) (where exposure to migrants is currently not considered) in SimaPro 8 software. LCI was collected for all life cycle stages from material acquisition to packaging disposal for European systems. The life cycle processes of HIPS chemical additives were not considered within the system boundaries for this case study. Details on the LCI processes considered are provided in Electronic Supplementary Material, Section S2 and Table S2.

\subsection{Chemicals in HIPS packaging material, migration, and effect data}

Gas or liquid-phase chemicals could transfer into food from caps or seals or from pre-washing or sanitizing solutions. For this study, we identified chemicals 
potentially migrating into food from HIPS packaging material only, and not from caps, seals, or washing solutions. To guide decision-making in practice, case studies should include in both the LCA, and the exposure modeling, caps, seals, and other closure devices as relevant. To test the application of the methodology and its relevance, we considered various consumer exposure scenarios. The first scenario was an "evidence-based" estimate that considered available data on the initial concentrations of chemicals in HIPS packaging material and a regulatory migration model to estimate $\mathrm{PiF}$. The other scenarios explored the order of magnitude of $\mathrm{CTU}_{\mathrm{h}}$ when considering various exposures at different levels of the legal migration limits. Legal limits were explored to provide the order of magnitude of a high-end exposure scenario and were not chosen to challenge existing safety regulations, or to predict actual or suspected damages caused by such exposure levels. Figure 1 demonstrates a basic work flow diagram to include exposure to chemicals in packaging (gray boxes) in the existing LCA framework (white boxes) either through Eq. (2) or (3).

\section{Fig. 1}

LCA work flow diagram: making LCAs of food packaging more comprehensive by considering chemicals contained in packaging, i.e., estimating impact using Eq. (2) as a function of the concentration of chemical in the food (C) and mass of food consumed $(\mathrm{mF})$ and effect factor (EF) or estimating impact using Eq. (1) as a function of the initial mass in the package $\left(\mathrm{mP}, 0_{\mathrm{P}, 0}\right)$ the product intake fraction $(\mathrm{PiF})$ and effect factor (EF).

Existing LCA framework

Additional steps

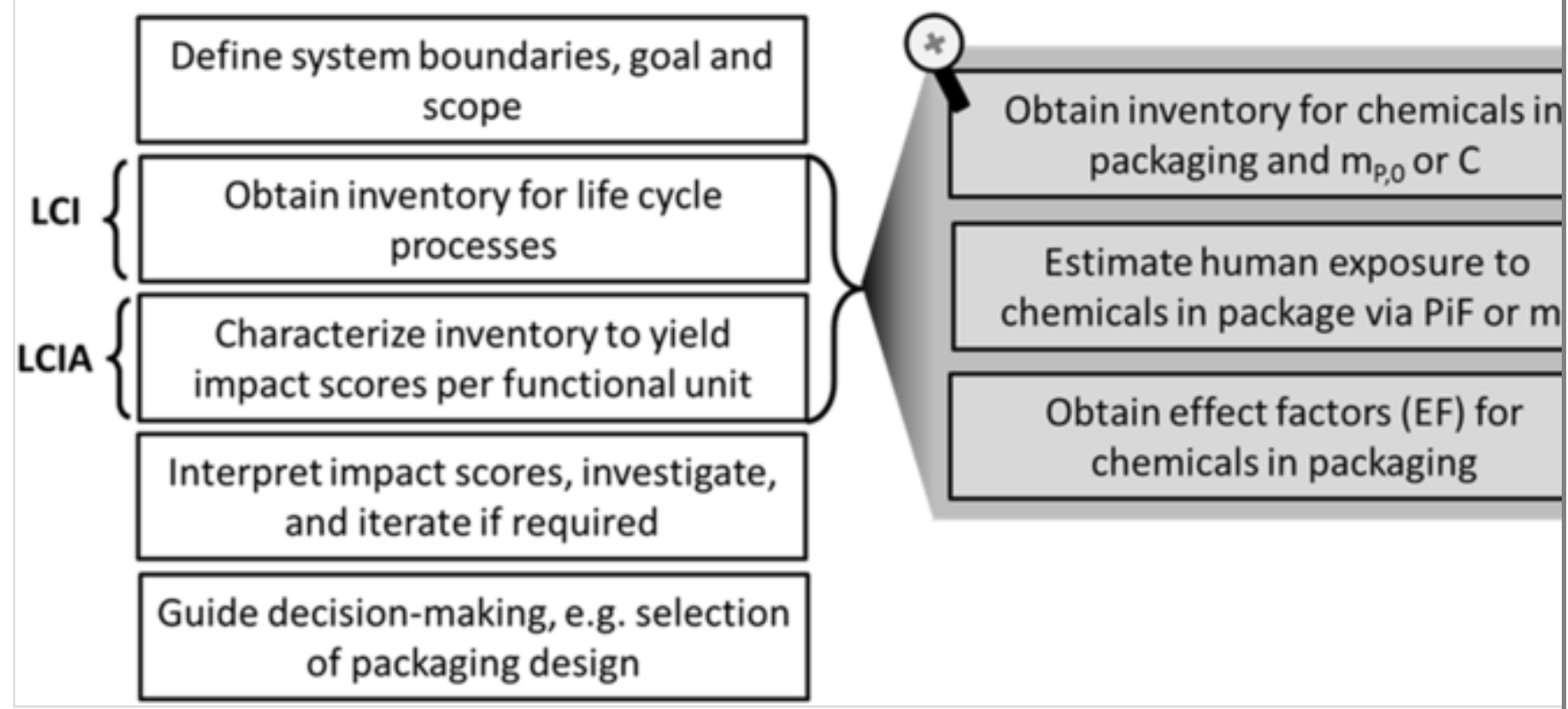

The steps on the right side of Fig. 1 (obtaining LCI of chemicals in packaging, estimating exposure, and effect factors) are described in more detail below. There 
is generally a lack of measured data on the concentration of various chemicals migrating from packaging into food, but LCA practitioners may be able to obtain results from migration modeling or analytical testing from a commissioning company. LCA practitioners may be able to obtain more information about the chemical additives used in a package from a study commissioner to develop LCI. For this proof-of-concept study, however, the list of chemicals in HIPS packaging material was collected from a US FDA study (Genualdi et al. 2014), regulatory documents from the European Commission (EC) (Hoekstra et al. 2015), and a technical report sponsored by the Food Standards Agency (Bradley and Coulier 2007).

In order to estimate $\mathrm{PiF}$ for the evidence-based scenario, a commonly used migration model was employed (Begley et al. 2005; Piringer and Baner 2008). Detailed information on the chemical concentrations, the migration modeling, and the initial masses in the package are available in the Electronic Supplementary Material, Section S3 and Table S1. Eq. tation (2) was then used to quantify $\mathrm{CTU}_{\mathrm{h}}$. For the "legal migration limits" scenarios, we considered EUspecific migration limits (SML) (Lierop et al. 1998; EC 2011; Hoekstra et al. 2015), which are the maximum concentrations ( $\mathrm{mg} / \mathrm{kg}$ ) allowable in food due to migration from packaging. When no SML was available the overall migration limit (OML) of $60 \mathrm{mg} / \mathrm{kg}$ of food was used. To obtain the value of $\mathrm{C}$ as required in Eq. (3), units were converted from the migration limit (ML) unit of $\mathrm{mg}$ of chemical per $\mathrm{kg}$ of food $(\mathrm{mg} / \mathrm{kg})$ to $\mathrm{kg} / \mathrm{kg}$. MLs are unlikely to be reached for some chemicals (e.g., styrene) (Linssen et al. 1993) but can be exceeded for others (e.g., some phthalates) (Tsumura et al. 2003). Results were explored at percentages of the legal limits not to demonstrate realistic scenarios, but to explore the order of magnitude of human toxicity impact scores and the relative contributions of different life cycle stages as the level of assumed exposure changes. In all scenarios whether "evidence-based" or "legal limit-based," we assumed that $100 \%$ of the packaged food was ingested, meaning food waste did not influence the estimation of $\mathrm{PiF}$ required in Eq. (1) or $\mathrm{m}_{\mathrm{f}}$ required in Eq. (2). Food waste could be included in future applications of this framework and may be important if two packaging designs are being compared that are associated with substantially different food spoilage.

To generally explore the coverage of currently available EFs for chemicals in food packaging and data needs, the Pew Charitable Trust (Neltner et al. 2013) list of 8105 chemicals legally allowable in food contact materials was matched to the USEtox (Rosenbaum et al. 2008) organic substances database. Given that few chemicals identified in HIPS packaging material could be matched to USEtox, we obtained data required to extrapolate EF from the Hazardous Substances Data Bank (HSDB) and the European Chemicals Agency (ECHA) web-based 
databases. In order of priority, ED50s, LOAELs, NOAELs, and LD50s were used to extrapolate EF (Huijbregts et al. 2005; Rosenbaum et al. 2011). The original toxicity reports for chemicals with an established SML were requested from RIVM. In all, the two total cancer and non-cancer IS $_{\mathrm{P}}$ were estimated as the sums of scores for all chemicals found to occur in HIPS (only styrene is relevant for the cancer impact score) and assumed to migrate into food, with either carcinogenic or non-carcinogenic effects, at or below their legal limits.

\section{Results}

\subsection{Human toxicity impacts of chemicals in HIPS in the life cycle context}

Forty-four chemicals were identified to possibly occur in HIPS packages, although their occurrence likelihood is unknown, and there could be fewer or more chemicals present in HIPS packaging materials on the market (Neltner et al. 2013; Genualdi et al. 2014; FDA 2015a). Seventeen out of 44 identified chemicals had concentrations in HIPS packaging material available through a US FDA study and a European Commission technical document (Genualdi et al. 2014; Hoekstra et al. 2015). Twenty chemicals out of the 44 identified had sufficient data to extrapolate EFs. Styrene (CAS 100-42-5), and phenol (CAS 108-95-2) were the only chemicals with an EF already available in USEtox for use in LCIA toxicity characterization. For greater perspective, we found out of the 8105 chemicals legally allowable in food contact materials (Neltner et al. 2013) that only 3\% (266 chemicals) had EFs already available in USEtox. Styrene was the only chemical we identified with a carcinogenic EF as styrene is "a reasonably anticipated carcinogen" (National Toxicology Program 2014), which is, however, not regulated as a carcinogen in food packaging. The carcinogenic EF was originally extrapolated from inhalation toxicity data, and we used a 1:1 route-to-route extrapolation for ingestion (Rosenbaum et al. 2011).

Given limited data availabilities, we were only able to identify seven chemicals in HIPS with both the reported initial concentration in packaging as well as data available for EF, required to obtain $\mathrm{CTU}_{\mathrm{h}}$ using Eq. (2) for the "evidence-based" scenario (Electronic Supplementary Material, Table S3). Six of these chemicals had data available to derive non-cancer EFs and one chemical, styrene, with both non-cancer and cancer EFs. For the "legal migration limit" scenarios, where each chemical was assumed to migrate at various levels of the maximum legal limit, the 20 identified chemicals with data available to obtain EF were used to estimate the impact scores using Eq. (3). Many of the chemicals in the "legal migration limit" scenarios did not have an SML available to our knowledge, and therefore, $60 \mathrm{mg} / \mathrm{kg}$ was used as the legally acceptable ML, according to 
regulation EC No 10/2011 (EC 2011). We do not determine if approaching or exceeding legal limits is realistic but consider it as an upper-limit scenario. A list of chemical MLs, their toxicity data, and the extrapolated EFs are provided in the Electronic Supplementary Material, Table S3.

The impact scores for cancer and non-cancer effects mediated by exposure to chemicals in food packaging, $\mathrm{IS}_{\mathrm{P}}$, and mediated by environmental life cycle emissions, $\mathrm{IS}_{\mathrm{e}}$, were compared to obtain a life cycle perspective and observe potential hotspots considering different magnitudes of consumer exposure. Interpretation of these results must be grounded in the assumptions of the LCIA framework, which does not predict disease cases, e.g., based on per-person exposures. We found that when migration was assumed to be $>0.1 \%$ of the legal limit for all of the characterizable HIPS migrants, non-cancer IS $_{\mathrm{P}}$ can be up to three orders of magnitude greater than the total $\mathrm{IS}_{\mathrm{e}}$ attributable to the hundreds of inventoried substances emitted to the environment over the entire HIPS life cycle (symbols in Fig. 2), and thus dominated the overall toxicity impact profile. When the considered chemicals occurred at assumed $<0.01 \% \mathrm{ML}$, their non-cancer human toxicity impacts were minor compared to the toxicity mediated via environmental emissions associated with the entire product life cycle.

\section{Fig. 2}

Relative contribution (left axis, bars) of human toxicity impact scores (IS) in comparative toxic units for life cycle stages and total values (right axis, symbols, note logarithmic scale). Impacts due to consumer exposure to HIPS migrants (IS ${ }_{\mathrm{P}}$ ) occurred in the use stage for an evidence-based scenario and six scenarios at or below legal migration limits for 20 chemicals. Impacts due to exposure of the population to environmental emissions $\left(\mathrm{IS}_{\mathrm{e}}\right.$ ) were aggregated over the life cycle for all chemicals related to the HIPS product life cycle. The IS for the transport stage were negligible and are not visible. 


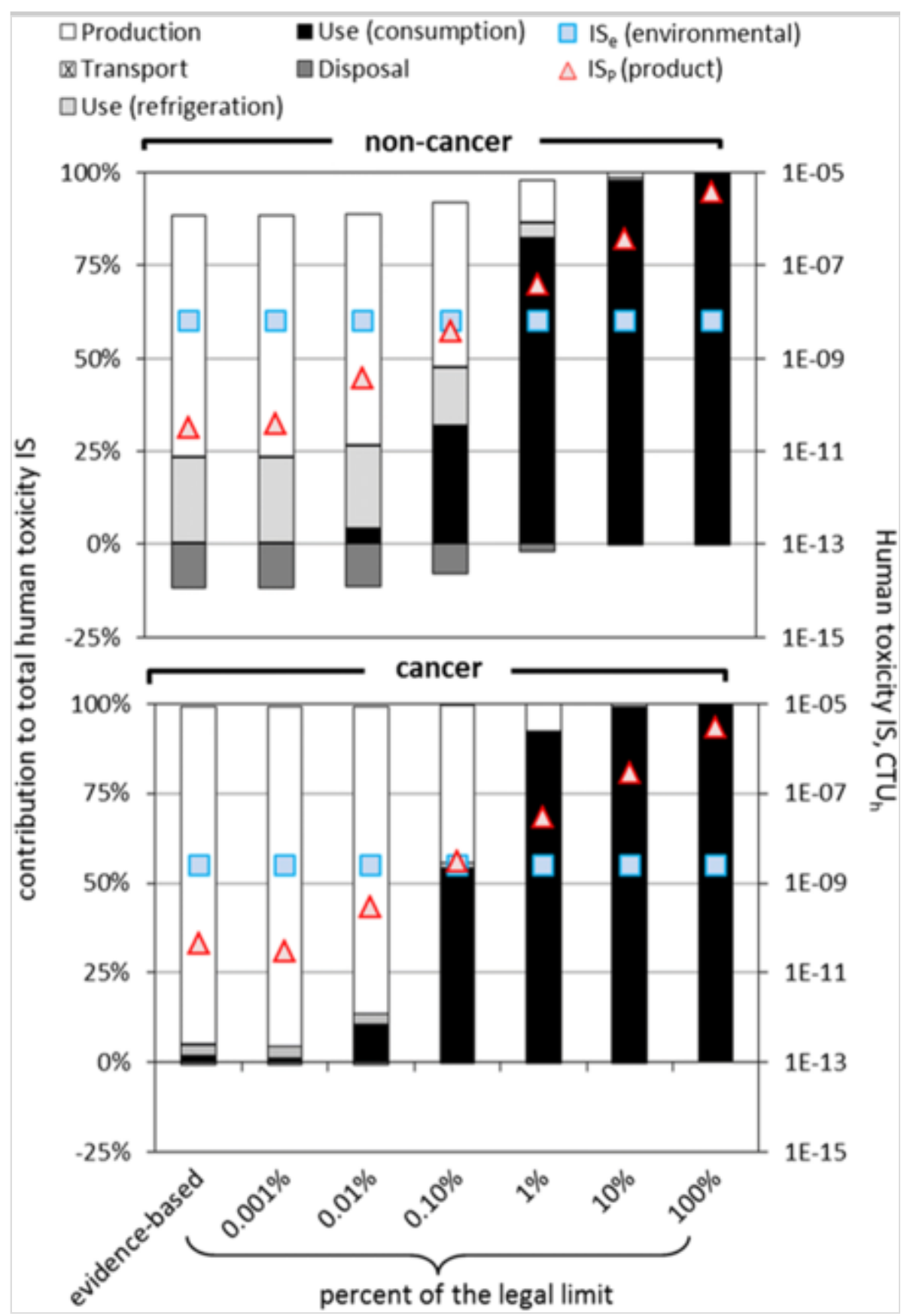

\section{Discussion}

Using the framework developed and tested in this study, we demonstrated consumer exposure to chemicals in food packaging can be considered in an LCA, when relevant for the goal and scope of the study, inventory data describing the initial chemical mass in a packaging material are available, and migration into food can be estimated (e.g. as PiF, see Sect. 2.2), and effect factors can be derived. In this study, we determine the requirements for adding an exposure pathway to the LCIA framework without altering the existing framework (Rosenbaum et al. 2008, 2011) for derivation of effect factors or estimation of human toxicity impacts. This study demonstrated use stage human toxicity scores for food packaging in an LCIA framework using HIPS as an example material selected because of data availability; this study did not attempt to perform a risk 
assessment or to estimate the maximum human health toxicity scores for food packaging.

Data limitations were substantial with respect to both-LCI, obtaining chemical concentrations in packaging materials, and LCIA with respect to the toxicity data for chemicals to derive effect factors, e.g., based on no observed adverse effect levels. Data on chemical concentrations in packaging materials can likely be obtained for individual case studies. Because empirical testing of food and biomonitoring is costly and time consuming, a LCIA-compatible model to estimate the migration of chemicals from packaging to food-as the product intake fraction, $\mathrm{PiF}$ (Jolliet et al. 2015) - is required to further operationalize the proposed exposure pathway in LCIA. The migration model used in this study (SI, Section S3) is a simplified diffusion-based model that assumes equilibrium between the chemical in packaging material and food has not been reached (which was assumed applicable in this relatively short case study or 14 days of shelf-life for yogurt). Adapting an accurate migration model to allow for pragmatic estimation of different chemicals in various food packaging scenarios, including long-term scenarios where equilibrium may be reached, is an essential need for future work. The FACET tool (Oldring et al. 2014) was recently developed to facilitate this goal; however, it is not applicable in LCIA because it provides estimates of exposures to chemicals in food packaging for a populationscale average given a pre-defined, undisclosed, and unchangeable market distribution for a given package-food combination, and thus cannot be adjusted to various functional units.

In addition to resolving exposure modeling issues, results underscore conceptual issues with interpreting human toxicity as comparative toxic unit $\left(\mathrm{a}-\mathrm{CTU}_{\mathrm{h}}\right.$ ) scores associated with potential levels of chemicals migrating from packaging materials into food. The human toxicity characterization framework in LCIA aims to manage exposure to potentially toxic substances in a life cycle, multiindicator context, even if a product is compliant with safety regulations. The LCIA methodology uses a human toxicity characterization framework pragmatically designed to relatively quickly compare complex systems and identify hotspots and trade-offs. Although the data used to derive toxicity-related effect factors in LCIA are the same data used to create safety regulations (i.e., built on dose-response curves from animal toxicity experiments), several key aspects of the framework are distinct from risk assessment and safety regulations. Mainly, exposure is not estimated per person per day and does not consider background exposure (i.e., average human exposure to chemicals through all sources) but is estimated with respect to a functional unit and a massbalance model to estimate intake by a population (Jolliet and Fantke 2015; Csiszar et al. 2016b). Thus, effect is not estimated with respect to per-person 
exposure thresholds but is a marginal change along a linear dose-response curve (Rosenbaum et al. 2011).

Given these differences between LCIA and safety regulations, when obtaining a $\mathrm{CTU}_{\mathrm{h}}$ in association with safe migration levels of chemicals in food packaging materials, the results suggest on one hand that including exposure to chemicals in food packaging in LCIA is meaningless given the current methods used to extrapolate effect and thus impact (at least for chemicals where a threshold of effect is well demonstrated). On the other hand, the methods and results suggest that including exposure to chemicals in consumer products can help indicate areas of priority where exposure to potentially toxic chemicals is highest. For example, in the "evidence-based" case of HIPS packaging (given only 7 chemicals within HIPS with data available to estimate exposure and effect) out of 44 identified, the life cycle emissions lead to a higher human toxicity impact score related to exposure to potentially toxic substances than exposure to chemicals in the package itself (see evidence-based scenario in Fig. 2). As another example, when exposures to the identified chemicals exceeded $0.1 \%$ of the legal migration limits, the associated human toxicity scores were a substantial hotspot across the life cycle. From an LCIA perspective, interpreting the human toxicity scores in $\mathrm{CTUh}_{\mathrm{h}}$ in association safe migration levels identify areas of prioritization to reduce human exposure to toxic substances and do not indicate actual measured increases in disease risk.

Epidemiological evidence suggests exposure to chemicals that occur in food packaging may be associated with various human outcomes that were not necessarily considered as effect measures in the animal experiments used to developed LCIA effect factors (e.g., related to allergy or neurological development of human fetuses) (Jaakkola and Knight 2008; Muncke 2011; Muncke et al. 2014; Bach et al. 2015; Ejaredar et al. 2015). This line of evidence suggests that including exposure to chemicals in food packaging into LCIA is needed to more comprehensively assess potential human health impacts related to product systems, but that the existing effect factor derivation from animal experiments requires further scrutiny.

Future work to develop EFs for chemicals in food packaging should consider novel focus on adapting in vitrein vitro or in silicein silico screening techniques that consider multiple biological mechanisms, e.g., related to endocrine disruption (e.g., Wetmore et al. 2015; Karmaus et al. 2016), as is being done in other screening techniques (Shin et al. 2015; Csiszar et al. 2016b). Furthermore, potential health impacts related to mixtures, endocrine disruptors, and other toxicity-related issues must be addressed as they are not generally covered by the single-chemical, high-dose, animal experiments that are currently used for safety 
regulations as well as the effect factors in LCIA - and are highly relevant for substances in food contact materials (Muncke 2011; Neltner et al. 2013; Geueke et al. 2014; Kortenkamp 2014). Developing human toxicity characterization methods to consider sensitive individuals, toxicity thresholds, background exposure, and mixtures has been discussed at a recent United Nations Environment Program (UNEP) and Society for Environment and Toxicology and Chemistry (SETAC) Life Cycle Initiative human toxicity workshop and in a recent publication by the US EPA (Csiszar et al. 2016b). Investigating such improvements in human toxicity characterization are a promising way forward to decrease the uncertainty of toxicity estimates in LCIA, improve result interpretability, and potentially align with other emerging risk-based approaches. Such changes in effect factor derivation would require complementary changes in exposure estimation, for example that consider background exposures and perperson exposure per day.

\section{Conclusions}

In this study, we extended LCIA to include consumer exposure to chemicals in food packaging. Using the developed methods, we performed a case study on HIPS material used for packaging yogurt, assuming different exposure scenarios for chemicals in HIPS. We considered exposures to the legal maximums of chemicals migrating from packaging into food (which may not occur in reality) as an "upper-bound," and we also considered other exposure scenarios such an "evidence-based" scenario given concentrations in packaging and migration modeling. Our findings demonstrated that generally including consumer product exposure pathways in LCIA leads to conceptual difficulty in interpreting the human toxicity impact scores. Human toxicity impact scores in LCIA are reported as comparative toxic units $\left(\mathrm{CTU}_{\mathrm{h}}\right)$ expressed as disease cases, even when exposures are within safety regulations. If such exposure can lead to measurable disease outcomes is a question of on-going scientific debate (Brewer and Ley 2011; Maffini et al. 2013; Kortenkamp 2014). The interpretation of these results would therefore be difficult to guide decision-making but can indicate which life cycle stage has higher potential for human toxicity. The "evidencebased" scenario built on the limited data available for chemicals in HIPS packaging material, starting concentration, and toxicity data, suggested that the human toxicity impact scores due to human exposure to environmental life cycle emissions far exceeded those due to exposure to chemicals in food packaging migrating into food. This study was unable to address occupational exposures and their importance in a life cycle context.

Our findings suggest that consumer exposure to chemicals in food packaging could be an important pathway to consider in LCAs of food packaging materials, 
and thus should be further explored. Recent concerns with "eco-friendly" and recycled materials containing potentially toxic chemicals emphasize potential trade-offs between exposure to chemicals and other environmental impacts (Lee et al. 2014; Yuan et al. 2016; Leslie et al. 2016). In order to include exposure to chemicals in food packaging in LCA, a practitioner would need to assess the relevance to the goal and scope of the study, obtain data on the occurrence and concentration of chemicals in food packaging (a part of Life Cycle Inventory gathering), and estimate migration from packaging into food (as a proxy for human exposure) and effect while iterating and interpreting each of these steps as needed. Effect factor modeling in LCIA should be a topic of future work in order to improve the interpretation of results, especially for exposure to chemicals in consumer products. Without improved data availabilities and effect factor modeling (e.g., that includes endocrine disruption), characterizing the toxicity of chemicals in food packaging in LCIA remains challenging and incomplete. To our knowledge, this was the first study to add consumer intake of chemicals in food packaging as an exposure pathway in LCIA, and the first study to attempt to quantify human toxicity impact scores related to exposure of chemicals in any consumer product during the use stage.

\section{Publisher's Note}

Springer Nature remains neutral with regard to jurisdictional claims in published maps and institutional affiliations.

\section{Acknowledgments}

The authors thank Olivier Jolliet, Philippe Roux, and David Amienyo for their feedback on this study.

\section{Funding information}

This work was financially supported by the Marie Curie projects Tox-Train (grant agreement no. 285286) and Quan-Tox (grant agreement no. 631910) funded by the European Commission under the Seventh Framework Programme. R. Rosenbaum received support from ANR (grant no. 13-CHIN-0005-01), SUEZ, BRL, SCP, Compagnie Fruitière, and VINADEIS.

\section{AQ3}

\section{Electronic supplementary material}

\section{ESM 1}

(DOCX $85 \mathrm{~kb})$ 


\section{References}

Apelberg BJ, Witter FR, Herbstman JB, Calafat AM, Halden RU, Needham LL, Goldman LR (2007) Cord serum concentrations of Perfluorooctane sulfonate (PFOS) and Perfluorooctanoate (PFOA) in relation to weight and size at birth. Environ Health Perspect 115:1670-1676

Bach CC, Bech BH, Brix N, Nohr EA, Bonde JPE, Henriksen TB (2015) Perfluoroalkyl and polyfluoroalkyl substances and human fetal growth: a systematic review. Crit Rev Toxicol 45:53-67

Begley TH, Hollifield HC (1995) Food packaging made form recycled polymers - functional barrier considerations. In: Rader CP, Baldwin SD, Cornell DD et al (eds) Plastics, rubber, and paper recycling: a pragmatic approach. Amer Chemical Soc, Washington, pp 445-457

Begley T, Castle L, Feigenbaum A, Franz R, Hinrichs K, Lickly T, Mercea P, Milana M, O'Brien A, Rebre S, Rijk R, Piringer O (2005) Evaluation of migration models that might be used in support of regulations for foodcontact plastics. Food Addit Contam 22:73-90

Belboom S, Renzoni R, Verjans B, Léonard A, Germain A (2011) A life cycle assessment of injectable drug primary packaging: comparing the traditional process in glass vials with the closed vial technology (polymer vials). Int $\mathrm{J}$ Life Cycle Assess 16:159-167

Biedermann M, Grob K (2013) Assurance of safety of recycled paperboard for food packaging through comprehensive analysis of potential migrants is unrealistic. J Chromatogr A 1293:107-119

Biryol D, Phillips K, Nicolas C, et al (2015) High-throughput dietary exposure predictions for chemical migrants from food packaging materials. https://cfpub.epa.gov/si/si_public_record_report.cfm?dirEntryId=311911 . Accessed 28 Aug 2017

Bradley E, Coulier L (2007) Report FD 07/01, An investigation into the reaction and breakdown products from starting substances used to produce food contact plastics. London: Central Science Laboratory 
Brewer PR, Ley BL (2011) Multiple exposures: scientific controversy, the media, and public responses to bisphenol a. Sci Commun 33:76-97

Csiszar SA, Ernstoff AS, Fantke P, Meyer DE, Jolliet O (2016a) Highthroughput exposure modeling to support prioritization of chemicals in personal care products. Chemosphere 163:490-498

Csiszar SA, Meyer DE, Dionisio KL et al (2016b) Conceptual framework to extend life cycle assessment using near-field human exposure modeling and high-throughput tools for chemicals. Environ Sci Technol 50:11922-11934

DG Environment, EC (2016) Strategic Plan 2016-2020. http://ec.europa.eu/atwork/synthesis/amp/doc/env_sp_2016-2020_en.pdf . Accessed 27 Oct 2016

Dhaliwal H, Browne M, Flanagan W, Laurin L, Hamilton M (2014) A life cycle assessment of packaging options for contrast media delivery: comparing polymer bottle vs. glass bottle. Int J Life Cycle Assess 19:1965-1973

EC (2011) EU Regulation 10/2011. http://eur-lex.europa.eu/legalcontent/EN/ALL/?uri=CELEX\%3A32011R0010 . Accessed 21 Nov 2016

EC-JRC (2014) ILCD handbook - EPLCA. http://eplca.jrc.ec.europa.eu/? page_id=86. Accessed 28 Apr 2014

EFSA (2017) Non-plastic food contact materials | European Food Safety Authority. https://www.efsa.europa.eu/en/topics/topic/non-plastic-foodcontact-materials . Accessed 8 Aug 2017

Ejaredar M, Nyanza EC, Ten Eycke K, Dewey D (2015) Phthalate exposure and childrens neurodevelopment: a systematic review. Environ Res 142:51-60

Ernstoff AS, Fantke P, Csiszar SA et al (2016) Multi-pathway exposure modeling of chemicals in cosmetics with application to shampoo. Environ Int 92-93:87-96

European Bureau for Conservation and Development (2015) Ensuring a nontoxic circular economy promotion of material cycles without hazardous substance. European Parliament, Brussels

European Parliament (2015) Don't allow recycling of plastics that contain toxic phthalate DEHP, Warn 
MEPs http://www.europarl.europa.eu/news/en/newsroom/20151120IPR03616/Don\%E2\%80\%99t-allow-recycling-of-plasticsthat-contain-toxic-phthalate-DEHP-warn-MEPs. Accessed 2 Apr 2016

Fantke P, Weber R, Scheringer M (2015) From incremental to fundamental substitution in chemical alternatives assessment. Sustain Chem Pharm 1:1-8

Fantke P, Ernstoff AS, Huang L, Csiszar SA, Jolliet O (2016) Coupled nearfield and far-field exposure assessment framework for chemicals in consumer products. Environ Int 94:508-518

FDA (2015a) CEDI Database

http://www.fda.gov/Food/IngredientsPackagingLabeling/PackagingFCS/CEDI/defa . Accessed 6 Apr 2016

FDA (2015b) Recycled plastics in food packaging. http://www.fda.gov/Food/IngredientsPackagingLabeling/PackagingFCS/RecycledP . Accessed 15 Aug 2016

FDA (2016) Guidance documents \& regulatory information by topicguidance for industry: preparation of premarket submissions for food contact substances: chemistry recommendations. http://www.fda.gov/Food/GuidanceRegulation/GuidanceDocumentsRegulatoryInfo . Accessed 16 Sep 2015

Flanigan L, Frischknecht R, Montalbo T (2013) An analysis of life cycle assessment in packaging for food and beverage applications. United Nations Environment Programme http://www.lifecycleinitiative.org/wpcontent/uploads/2013/11/food_packaging_11.11.13_web.pdf. Accessed 15 Sep 2015

Genualdi S, Nyman P, Begley T (2014) Updated evaluation of the migration of styrene monomer and oligomers from polystyrene food contact materials to foods and food simulants. Food Addit Contam Part A 31:723-733

Gérand Y, Roux P (2014) Novinpak ${ }^{\circledR}$ system life cycle assessment, comparative life cycle assessment of the Novinpak ${ }^{\circledR}$ PET bottle vs. traditional glass bottle including win manufacturing. UMR ITAP, ELSA group, France

Geueke B, Wagner CC, Muncke J (2014) Food contact substances and chemicals of concern: a comparison of inventories. Food Addit Contam Part 
Hauschild MZ, Huijbregts MAJ (eds) (2015) Life cycle impact assessment. Springer Netherlands, Dordrecht

Hauschild MZ, Huijbregts M, Jolliet O, Macleod M, Margni M, van de Meent D, Rosenbaum RK, McKone TE (2008) Building a model based on scientific consensus for life cycle impact assessment of chemicals: the search for harmony and parsimony. Environ Sci Technol 42:7032-7037.

https://doi.org/10.1021/es703145t

Hellweg S, Demou E, Bruzzi R, Meijer A, Rosenbaum RK, Huijbregts MAJ, McKone TE (2009) Integrating human indoor air pollutant exposure within life cycle impact assessment. Environ Sci Technol 43:1670-1679

Hoekstra EJ, Brandsch R, Dequatre C et al (2015) Practical guidelines on the application of migration modelling for the estimation of specific migration. European Commission, Joint Research

Centre. http://publications.jrc.ec.europa.eu/repository/bitstream/JRC98028/reqno \%20annex\%2010\%20-\%20pubsy.pdf Accessed 3 Feb 2016

Huang L, Jolliet O (2016) A parsimonious model for the release of volatile organic compounds (VOCs) encapsulated in products. Atmos Environ 127:223-235

Huang L, Ernstoff A, Fantke P, Csiszar SA, Jolliet O (2017) A review of models for near-field exposure pathways of chemicals in consumer products. Sci Total Environ 574:1182-1208

Huijbregts MAJ, Rombouts LJA, Ragas AMJ, van de Meent D (2005) Human-toxicological effect and damage factors of carcinogenic and noncarcinogenic chemicals for life cycle impact assessment. Integr Environ Assess Manag 1:181-244. https://doi.org/10.1897/2004-007R.1

Humbert S, Rossi V, Margni M, Jolliet O, Loerincik Y (2009) Life cycle assessment of two baby food packaging alternatives: glass jars vs. plastic pots. Int J Life Cycle Assess 14:95-106

Hunt RG, Franklin WE (1996) LCA—how it came about. Int J Life Cycle Assess 1:4-7 
Jaakkola JJK, Knight TL (2008) The role of exposure to phthalates from polyvinyl chloride products in the development of asthma and allergies: a systematic review and meta-analysis. Environ Health Perspect 116:845-853

Jolliet O, Fantke P (2015) Human toxicity. In: Hauschild MZ, Huijbregts MAJ (eds) Life cycle impact assessment. Springer Netherlands, Dordrecht, pp 7596

Jolliet O, Ernstoff AS, Csiszar SA, Fantke P (2015) Defining product intake fraction to quantify and compare exposure to consumer products. Environ Sci Technol 49:8924-8931

JRC (2015) European Life Cycle

Database. http://eplca.jrc.ec.europa.eu/ELCD3/ Accessed 15 Sep 2016

Karmaus AL, Filer DL, Martin MT, Houck KA (2016) Evaluation of foodrelevant chemicals in the ToxCast high-throughput screening program. Food Chem Toxicol 92:188-196

Kortenkamp A (2014) Low dose mixture effects of endocrine disrupters and their implications for regulatory thresholds in chemical risk assessment. Curr Opin Pharmacol 19:105-111

Lee J, Pedersen AB, Thomsen M (2014) The influence of resource strategies on childhood phthalate exposure - the role of REACH in a zero waste society. Environ Int 73:312-322

Leslie HA, Leonards PEG, Brandsma SH, de Boer J, Jonkers N (2016) Propelling plastics into the circular economy - weeding out the toxics first. Environ Int 94:230-234

Linssen JPH, Janssens ALGM, Reitsma HCE, Bredie WLP, Roozen JP (1993) Taste recognition threshold concentrations of styrene in oil-in-water emulsions and yoghurts. J Sci Food Agric 61:457-462

Maffini MV, Alger HM, Olson ED, Neltner TG (2013) Looking back to look forward: a review of FDA's food additives safety assessment and recommendations for modernizing its program. Compr Rev Food Sci Food Saf $12: 439-453$ 
Muncke J (2011) Endocrine disrupting chemicals and other substances of concern in food contact materials: an updated review of exposure, effect and risk assessment. J Steroid Biochem Mol Biol 127:118-127

Muncke J, Myers JP, Scheringer M, Porta M (2014) Food packaging and migration of food contact materials: will epidemiologists rise to the neotoxic challenge? J Epidemiol Community Health 68:592-594

National Toxicology Program (2014) Report on Carcinogens, Thirteenth Edition: Styrene. https://ntp.niehs.nih.gov/ntp/roc/content/profiles/styrene.pdf . Accessed 9 Sep 2016

Neltner TG, Alger HM, Leonard JE, Maffini MV (2013) Data gaps in toxicity testing of chemicals allowed in food in the United States. Reprod Toxicol 42:85-94

Oldring PKT, O’Mahony C, Dixon J, Vints M, Mehegan J, Dequatre C, Castle L (2014) Development of a new modelling tool (FACET) to assess exposure to chemical migrants from food packaging. Food Addit Contam Part Chem Anal Control Expo Risk Assess 31:444-465

Pelletier N (2015) Life cycle thinking, measurement and management for food system sustainability. Environ Sci Technol 49:7515-7519

Pini M, Salieri B, Ferrari AM, Nowack B, Hischier R (2016) Human health characterization factors of nano-TiO2 for indoor and outdoor environments. Int J Life Cycle Assess 21:1452-1462

Piringer OG, Baner AL (2008) Plastic packaging materials for food: barrier function, mass transport, quality assurance, and legislation. Wiley Weinheim, Germany, pp 79-157

Poças M de F, Hogg T (2007) Exposure assessment of chemicals from packaging materials in foods: a review. Trends Food Sci Technol 18:219-230

Prüss-Ustün A, Vickers C, Haefliger P, Bertollini R (2011) Knowns and unknowns on burden of disease due to chemicals: a systematic review. Environ Health 10:9

Rosenbaum RK, Bachmann TM, Gold LS, Huijbregts MAJ, Jolliet O, Juraske R, Koehler A, Larsen HF, MacLeod M, Margni M, McKone TE, Payet J, 
Schuhmacher M, van de Meent D, Hauschild MZ (2008) USEtox - the UNEPSETAC toxicity model: recommended characterisation factors for human toxicity and freshwater ecotoxicity in life cycle impact assessment. Int J Life Cycle Assess 13:532-546

Rosenbaum R, Huijbregts M, Henderson A et al (2011) USEtox human exposure and toxicity factors for comparative assessment of toxic emissions in life cycle analysis: sensitivity to key chemical properties. Int J Life Cycle Assess 16:710-727

Rosenbaum RK, Meijer A, Demou E, Hellweg S, Jolliet O, Lam NL, Margni M, McKone TE (2015) Indoor air pollutant exposure for life cycle assessment: regional health impact factors for households. Environ Sci Technol 49:12823-12831

Shin H-M, Ernstoff AS, Arnot JA, Wetmore BA, Csiszar SA, Fantke P, Zhang X, McKone TE, Jolliet O, Bennett DH (2015) Risk-based high-throughput chemical screening and prioritization using exposure models and in vitro bioactivity assays. Environ Sci Technol 49:6760-6771

Swan SH, Main KM, Liu F, Stewart SL, Kruse RL, Calafat AM, Mao CS, Redmon JB, Ternand CL, Sullivan S, Teague JL, the Study for Future Families Research Team (2005) Decrease in anogenital distance among male infants with prenatal phthalate exposure. Environ Health Perspect 113:10561061

Tsumura Y, Ishimitsu S, Saito I et al (2003) Estimated daily intake of plasticizers in 1-week duplicate diet samples following regulation of DEHPcontaining PVC gloves in Japan. Food Addit Contam 20:317-324

$\tan$ Lierop B, Castle L, Feigenbaum A, Boenke A (1998) Spectra for the identifieation of additives in food packaging. Springer Seience \& Business Media Dordrecht, Netherlands

Weidema BP, Bauer C, Hischier R et al (2013) The ecoinvent database: overview and methodology, Data quality guideline for the ecoinvent database version 3, www.ecoinvent.org. Accessed 15 Sep 2016 AQ5

Wetmore BA, Wambaugh JF, Allen B, Ferguson SS, Sochaski MA, Setzer RW, Houck KA, Strope CL, Cantwell K, Judson RS, LeCluyse E, Clewell HJ, 
Thomas RS, Andersen ME (2015) Incorporating high-throughput exposure predictions with dosimetry-adjusted in vitro bioactivity to inform chemical toxicity testing. Toxicol Sci 148:121-136

World Economic Forum and Ellen MacArthur Foundation (2016) The new plastics economy: rethinking the future of plastics.

http://www.ellenmacarthurfoundation.org/publications/the-new-plasticseconomy-rethinking-the-future-of-plastics . Accessed 18 Apr 2016

Yuan G, Peng H, Huang C, Hu J (2016) Ubiquitous occurrence of fluorotelomer alcohols in eco-friendly paper-made food-contact materials and their implication for human exposure. Environ Sci Technol 50:942-950 